\title{
The Crisis Facing Terrestrial Broadcasters and Reorganization Policy of Television Industry
}

\author{
Joon-Ho Lee1)
}

\begin{abstract}
This study analyzes the current serious environmental conditions within the Korean broadcasting industry in order to propose theoretical and practical solutions to help cope with them. Based on analyses of data and literature regarding TV industries, digital and multimedia technologies that produce and transmit broadcast content have ended the dominating power of terrestrial TV. The power has been transferred to the three large telecommunication companies, pay TV service providers, and on-line content providers. The evidence shows that a diverse effort is needed to redefine the term 'broadcasting', using a new range structure and a new philosophy of broadcasting. This will strengthen locality by redeploying coverage areas and markets, and by reconceptualizing the term 'public interest'. In order to achieve these goals, broadcasters in conjunction with governmental broadcast authorities should observe these changes, and respond to the new environment with great care. They must also continue to serve their primary functions in terms of locality, diversity, autonomy, and fairness to regenerate the loyalty of audience and advertisers.
\end{abstract}

Keywords : Broadcasting, Media, Policy, Competition, Public Interest, Audio-visual Service

\section{Introduction - Intent of the Study}

Broadcasting industries, in the traditional sense, are currently in a state of collapse. In addition to terrestrial broadcasting systems, a variety of video services that look similar have emerged, and these services compete at an overwhelming rate. This is due to a technological revolution that began in the 1990s in which digital and multimedia technologies and media converged with diverse video service outlets and a variety of smart devices. These environmental changes have made traditional broadcasting services face increasing difficulties in their general operations and advertising sales. Since terrestrial TV signals were entirely transformed to a digital format in the 2010s, their influence and profit-making ability have been steadily shrinking. This is because of decreases in their rating, revenue, and advertising share lost to

Received(April 19, 2019), Review Result(1st: May 11, 2019, 2nd: July 2, 2019), Accepted(September 10, 2019)

1) (Professor) 47340 Department of Communication \& Media, Dong-eui Univ., Eomgwangno 176, Busanjin-gu, Busan, Korea e-mail: joonlee@deu.ac.kr 
pay (subscription) TV services and the plethora of on-line video and information services.

Originally terrestrial broadcasting is designed to utilize the natural frequency spectrum for their main transmission channels and this was considered as a scarce resource in a country. As a result, their programs and products have been categorized as a public good served free of charge compared to those produced by their pay and on-line counterparts. Terrestrial broadcast systems are also subject to stronger governmental laws and regulations in order to promote the public interest. This stronger scrutiny extends to are as of license renewal, general operation, content, programming, personnel, and advertising sales. Furthermore, terrestrial TV programs and content are easily accepted and illegally distributed on the web by many video service formats such as VOD (Video on Demand) and streaming with little or no compensation. These factors have restrained terrestrial broadcasters from stable growth and profitability.

Another related issue within the broadcast industry has been the unclear range and definition of the term 'broadcasting.' Domestically and internationally, the concept of broadcasting has expanded due to innumerable amount of surplus content on, devices, services, and through business parties that have emerged reaching a mass audience with a variety of services and focus points that were exclusively provided by conventional broadcasting systems. This transformation was so powerful that it has become known as a 'media big-bang'[1]. Even though this phenomenon has generated an abundance of choice for content users that can be seen as positive, on the other hand, it has also caused many problems and conflicts to arise among broadcasters and video service providers regarding copyright and intellectual property issues. These issues have centered on the very nature of transmission content and also the need for fair competition among the plethora of legally differentiated media. It is also clear that these challenges have come to the forefront more and more in recent several years. As a result, there have been a series of academic and legal debates among Korean broadcasters and policy-makers on how to determine the scope and definition of broadcasting. This task cannot be easily performed because the diverse video services have blurred the boundary between broadcasting and non-broadcasting content and services.

In this study, the current financial state of broadcasters in terms of their competitiveness will be analyzed, and then some possible ideas that could clarify these blurred conceptual boundaries were suggested. In order to do achieve these objectives, Korean governmental statistical policy data for the years 2013-2018 are collected and synthesized as secondary content analysis data. In addition, a review of the literature and relevant conference papers concerning the theoretical conceptualization of broadcasting and video services will be conducted. 


\section{The New Broadcasting Environment and Competition}

The Korean broadcasting and video service market is full of diverse players who provide similar programs and contents using different platforms and networks. This transformation began as early as 1995 with the start of legitimate multichannel cable TV systems capable of providing more than 30 new television channels in addition to four preexisting network channels as well as a local independent channel. Shortly thereafter, a new satellite TV platform, entitled Skylife began transmitting the same channels wirelessly in early 2000s. Later, in 2010s, IPTV was launched as a new form of TV platform owned and operated by three major telecommunication companies that used high-speed Internet. Currently, there are more than 300 legal TV channels and hundreds of pseudo broadcast services such as those by OTTs and web streaming services that have entered and serve the viewing market. in some cases, they provide almost identical content and in others the content is very similar to that of traditional broadcasters. The difference is that these new systems use wired or wireless Internet transmission of content. The majority of the viewing public do not perceive a difference between these types of systems since most TV content in Korea can now be also viewed on any digital device[2].

The problem for traditional broadcasters however is that stricter policies and regulations are being applied to these long standing TV platforms and program sources. Except the terrestrial TV, the majority of TV services collect pay subscription from their users as well as increased revenues from more liberalized advertising sales. For these reasons, as shown in the Fig. 1, 2, 3, below, the financial status and social influence of terrestrial TV has visibly shrunk[3]. Even though terrestrial broadcasters ask the pay counterparts for their program copyrights and receive retransmission fees which are certain amounts of payments terrestrial broadcasters collect from pay TV platforms that retransmit terrestrial TV signals based on the number of pay TV subscribers.

During the period from 2013 to 2017, the total revenue of terrestrial broadcasters gradually decreased, and their total advertising revenues rapidly decreased. [Fig. 1] and [Fig. 2] demonstrate that they have actively sought alternative revenue resources from retransmission fees, sponsorships, and diversification in order to compensate for the loss of advertising revenue to web and mobile counterparts.

[Fig. 3] demonstrates the current trend of profitability levels among Korean terrestrial broadcasters. Each broadcaster shows a different trend in their net profit throughout the last 
five years. KBS, EBS, and local independent stations had relatively strong growing profits whereas those of MBC and SBS decreased over time. In the case of MBC, there was a big deficit in the most recent year. It shows the more dependent on advertising revenues a broadcast is, the less profit they have been able to generate.

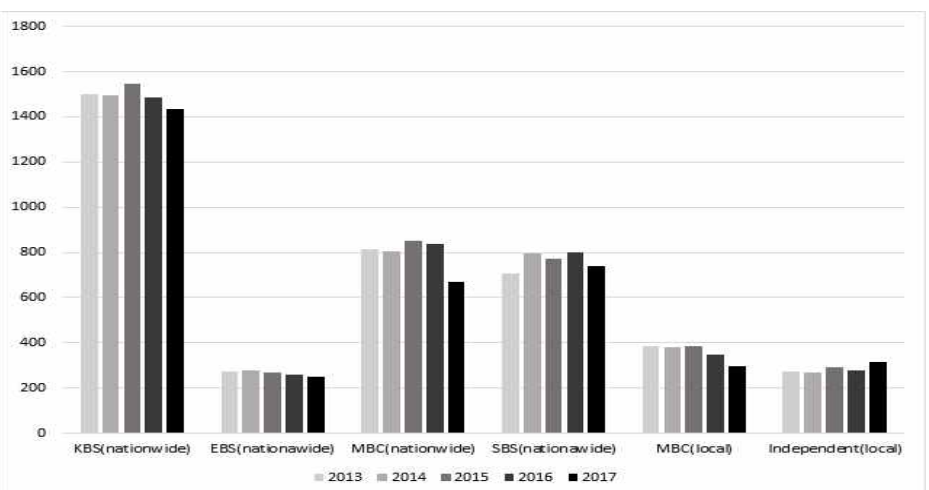

[Fig. 1] The Total Revenues of Korean Terrestrial Broadcasters (unit: bil. Won)

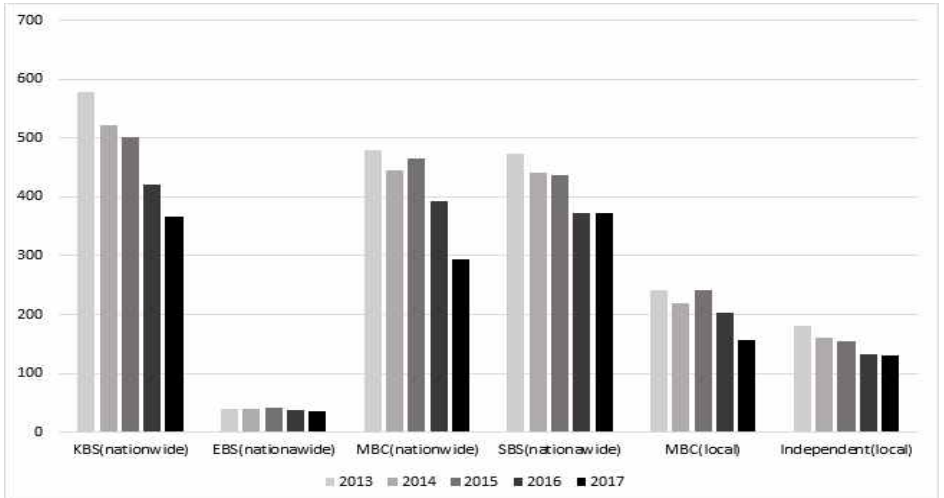

[Fig. 2] The Total Advertising Revenue for Korean Terrestrial Broadcasters (unit: bil. Won)

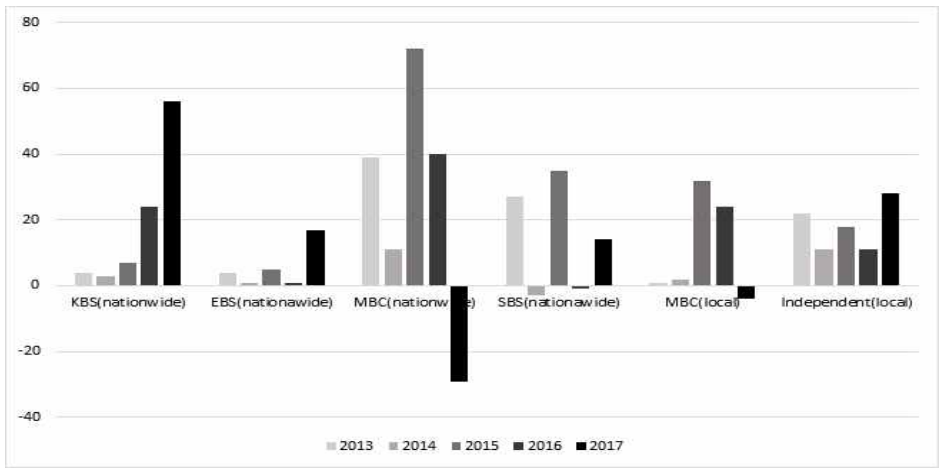

[Fig. 3] Net Profits of Korean Terrestrial Broadcasters (unit: bil. Won) 
Vol.5, No.3, September 30 (2019), pp. 31-40 http://dx.doi.org/10.21742/apjcri.2019.09.04

In terms of annual revenue share and growth rate, 27 local terrestrial stations share only $16.6 \%(8.0 \%+8.6 \%)$ of the total revenues as shown in [Table 1][4]. There has been a shrinking trend for total revenue due to recent diversification of advertising media because of legal restrictions on terrestrial advertising. This resulted in very small revenue share of local broadcasters in comparison with the number of stations in service. This means that the discrepancy of advertising revenue between national and regional broadcasters has increased, and local advertising markets have been shrinking faster. This fact supports the argument that policy considerations for local broadcasters are needed in the current broadcasting environment.

[Table 1] The Revenue Share and Growth Rate of Korean Broadcasters

\begin{tabular}{|c|r|r|}
\hline Broadcasters(\# of Stations) & \multicolumn{1}{c|}{$\begin{array}{l}\text { Share } \\
(2017)\end{array}$} & $\begin{array}{l}\text { Average Growth } \\
\text { Rate (2013-2017) }\end{array}$ \\
\hline KBS (nationwide)(1) & $38.7 \%$ & $-1.1 \%$ \\
\hline MBC (nationwide)(1) & $18.1 \%$ & $-4.3 \%$ \\
\hline SBS (nationwide)(1) & $19.9 \%$ & $1.3 \%$ \\
\hline EBS (nationwide)(1) & $6.8 \%$ & $-1.9 \%$ \\
\hline Local MBC(17) & $8.0 \%$ & $-5.9 \%$ \\
\hline Local Independent Stations(10) & $8.6 \%$ & $-0.9 \%$ \\
\hline Total (Terrestrial TV) & $100 \%$ & $2.3 \%$ \\
\hline Total (Pay TV) & $100 \%$ & \\
\hline
\end{tabular}

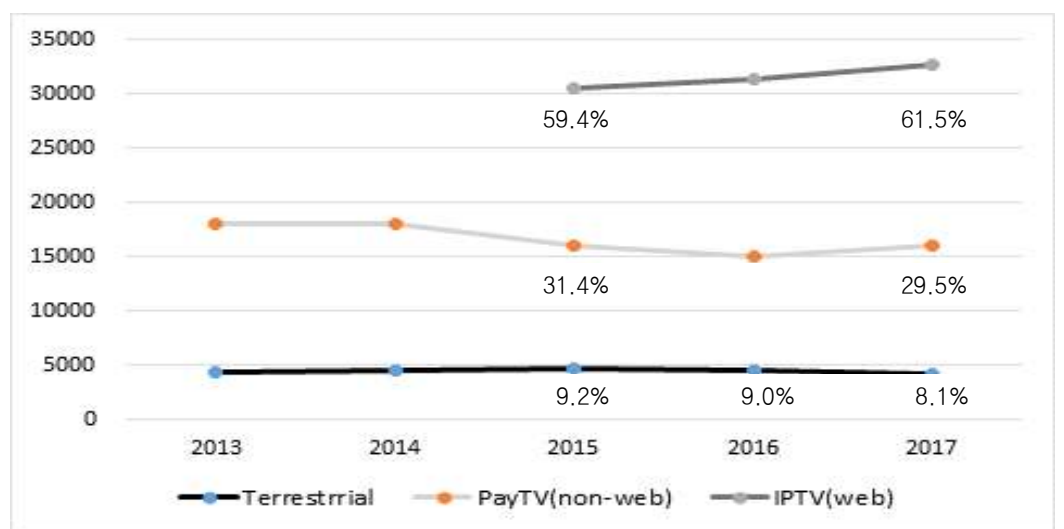

[Fig. 4] Total Revenues and Shares of Broadcasting Industry under Regulation (unit: bil. Won)

Compared to the decreasing average growth rates of terrestrial broadcasters, the growth rate of pay TV players is relatively positive ([Table 1] and [Fig. 4]). Their average annual growth rate of total revenues is $2.3 \%$ and their increased share of revenues in the industry accounts for over $90 \%$ of the growth. It means that viewers have been more likely to subscribe to pay TV, and that advertisers are now in favor of pay TV strategically. 


\section{The Range and Definition of Broadcasting}

In general, broadcasting has been defined as an electronic mass communication system that produces or buys and transmits free public and universal audio-visual signals or contents over the air following certain time schedule directed at large, heterogeneous, and scattered audiences with a receiving device. Therefore, the definition of conventional terrestrial broadcasting is closest to that of 'broadcasting.' Also, the majority of broadcasting regulation systems in the world are operated within vertical and asymmetrical regulation. This type of regulation requires terrestrial broadcasters to meet such guidelines as serving stronger public interest, completing more frequent license renewals, and providing more decent content, than do pay TV counterparts[5]. This fact has caused the economic shrinkage of terrestrial broadcasters that was illustrated above. It supports the case for a new regulation system that is more horizontal and symmetrical. In short, the same service should have that same regulation regardless of the difference in broadcast platforms[6].

In order to revitalize terrestrial broadcasters, equivalent regulation throughout all audio-visual media services must be established. This can be begun by redefining and re-categorizing each of these services. The first solution is to use a media matrix [Fig. 5] and this will in turn provide a conceptual frame to compare the characteristics of each media business according to its level of function, value, and right to exist[7].

\begin{tabular}{|c|c|c|c|c|c|c|c|}
\hline Function & $\begin{array}{l}\text { Talent } \\
\text { Purchase }\end{array}$ & $\begin{array}{l}\text { Content } \\
\text { Production }\end{array}$ & $\begin{array}{l}\text { Intrachannel } \\
\text { Programming }\end{array}$ & $\begin{array}{c}\text { Content } \\
\text { Accumulation }\end{array}$ & $\begin{array}{l}\text { Interchannel } \\
\text { Programming }\end{array}$ & Transmit & Arrival \\
\hline Value & \multicolumn{3}{|c|}{ Production of Value } & \multicolumn{3}{|c|}{ Value Transfer \& Added Value } & $\begin{array}{l}\text { Value } \\
\text { Implementation }\end{array}$ \\
\hline Right & \multicolumn{2}{|c|}{ Content Party } & & \multicolumn{3}{|c|}{ Service Party } & \\
\hline \multirow[b]{2}{*}{ Business } & Agency & Producer & Programmer & \multicolumn{3}{|c|}{ Platform Service } & Device \\
\hline & 1 Copyright & \multicolumn{2}{|c|}{$\begin{array}{l}\text { Conventional } \\
\text { TV Production }\end{array}$} & Content & imulation & Network & (SetTop) \\
\hline Terrestrial & $\mathrm{O}$ & $\mathrm{O}$ & $\mathrm{O}$ & $\triangle$ & $\triangle$ & $\mathrm{O}$ & $\triangle$ \\
\hline Pay TV PP & $\mathrm{O}$ & $\mathrm{O}$ & 0 & $\mathrm{X}$ & $\mathrm{X}$ & $\mathrm{X}$ & $\mathrm{X}$ \\
\hline Pay Platform & $\mathrm{X}$ & $\mathrm{X}$ & $\mathrm{X}$ & $\mathrm{O}$ & $\mathrm{O}$ & $\mathrm{O}$ & $\mathrm{O}$ \\
\hline Google & $\mathrm{X}$ & $\mathrm{X}$ & $\mathrm{X}$ & $\mathrm{O}$ & $\mathrm{O}$ & $\mathrm{O}$ & $\mathrm{X}$ \\
\hline Naver & $\mathrm{O}$ & $\mathrm{X}$ & $\triangle$ & $\mathrm{O}$ & $\mathrm{O}$ & $\mathrm{O}$ & $\mathrm{X}$ \\
\hline Netflix & $\mathrm{O}$ & $\mathrm{O}$ & $\triangle$ & $\mathrm{O}$ & $\triangle$ & $\triangle$ & $\mathrm{X}$ \\
\hline
\end{tabular}

[Fig. 5] Media Matrix 
Vol.5, No.3, September 30 (2019), pp. 31-40 http://dx.doi.org/10.21742/apjcri.2019.09.04

Most elements of this frame can successfully be applied to terrestrial broadcasters and pay TV PPs and platforms(cable, satellite, and IPTV), but not to on-line video services such as Google, OTTs(Over-the-Top), portals, and Youtube, etc. This means that the newcomers in these video industries prepare themselves with niche strategies to avoid inefficient financial operation. Thes newcomers use specialized functions and services to attain their current status and this is one requiring less governmental regulation.

The second solution is to consider justification in redefining broadcasting according to a series of questions: 'whose perspective?' 'why?' 'what purpose?' 'how?' and 'what principle?'[8] When answering them, the following additional criteria should be considered: (1) The perspectives of stockholders, regulating authorities, citizens, consumers, related industries, and academic theories should be considered. (2) The reasons behind environmental changes must be considered in light of technological change, equal competition, public interest, and political interests. (3) The purpose of the medium including those values of technology, market, industry, culture, politics, and society. (4) The specific method used for categorization; expansion, maintenance, reduction, or replacement/removal for whole or partial ranges within the concept of broadcasting.

[Table 2] Legal Categorization of Audio-Visual Services and Regulation

\begin{tabular}{|c|c|c|c|}
\hline Nation/Block & $\begin{array}{c}\text { Categorization of } \\
\text { Audio-Visual Media }\end{array}$ & Laws of Rationale & Core points of Regulation \\
\hline USA & $\begin{array}{l}\text { - Broadcast TV } \\
\text { - MVPD (Multichannel Video } \\
\text { Programming Distributor) } \\
\text { - OVD (Online Video } \\
\text { Distributor) }\end{array}$ & $\begin{array}{l}\text { - Communications Act of } 1934 \\
\text { - Telecommunications Act of } \\
1996\end{array}$ & $\begin{array}{l}\text { - Effective competition } \\
\text { - No direct content regulation } \\
\text { and no Ad. regulation } \\
\text { - Retransmission consent and fair } \\
\text { trade } \\
\text { - Weak expansion of range }\end{array}$ \\
\hline $\mathrm{EU}$ & $\begin{array}{l}\text { - ECN (Electronic } \\
\text { Communications Network) } \\
\text { - ECS (Electronic } \\
\text { Communications Services) } \\
\text { - AVMV (Audio-Vidual Media } \\
\text { Services): linear/on-demand }\end{array}$ & $\begin{array}{l}\text { - RFEC (Regulatory Framework } \\
\text { for Electronic Communications) } \\
\text { - ECD (Electronic } \\
\text { Communications Directive) } \\
\text { - AVMSD (Audio-Visual Media } \\
\text { Services Directive) }\end{array}$ & $\begin{array}{l}\text { - Consumer protection } \\
\text { - Distinguishing Ad. from content } \\
\text { (Transparency) } \\
\text { - No discrimination and no } \\
\text { hatred (Public interest) } \\
\text { - Intra-Europe Interchange } \\
\text { (Accessibility) }\end{array}$ \\
\hline UK & $\begin{array}{l}\text { - } \text { Real-time Broadcasting } \\
\text { Channels (DTPS/TLCS) } \\
\text { - ODS (On-Demand } \\
\text { Programming Service) } \\
\text { - The other }\end{array}$ & $\begin{array}{l}\text { - Communications Act } 2003 \\
\text { - Audiovisual Media Service } \\
\text { Regulations } 2009\end{array}$ & $\begin{array}{l}\text { - Recognition and Protection of } \\
\text { Consumers } \\
\text { - No harmful content } \\
\text { - Ad. regulation }\end{array}$ \\
\hline S. Korea & $\begin{array}{l}\text { - Broadcast TV (public } \\
\text { owned/non-publically owned, } \\
\text { universal/pay services) } \\
\text { - Value-added communication } \\
\text { services }\end{array}$ & $\begin{array}{l}\text { - Broadcasting Law } 2013 \\
\text { - Telecommunications Act }\end{array}$ & $\begin{array}{l}\text { - Public interest and fairness } \\
\text { - Content promotion and } \\
\text { regulation } \\
\text { - Ad. regulation } \\
\text { - Expansion of range }\end{array}$ \\
\hline
\end{tabular}


In terms of the third solution, it is important to analyze and compare the recent regulatory trends among advanced nations such as USA, EU, and UK [Table 2][9][10]. Recently, the USA and the EU defined broadcast media as conventional terrestrial TV only, while the UK and South Korea have a more comprehensive meaning of broadcast media, including terrestrial, cable, IPTV, and satellite platforms. All the countries listed do not consider OTT services as broadcasting. Most countries apply asymmetrical (vertical) regulation to different media in order to promote the public interest regulate the well-fair of consumers (users) through content and advertising. This is applied more extensively to terrestrial broadcasters.

\section{Revision and Revitalization}

The rapid and large-scale changes in audio-visual media outlets invite expansionism and most new audio-visual media should be included to or categorized as new types of broadcasting. From users' perspective, the majority of people tend to induce their own cognitive experience and schema when facing a new phenomenon they have not yet experienced. For example, most people in Korea tend to call the new audio-visual media 'broadcasting' or 'television.' From the perspective of regulation authorities, they also tend to include the new media or services into the present regulatory frame of broadcasting. It can best be described as an interventionist or paternalistic perspective[10]. Both parties commonly believe that the new audio-visual media and services also must uphold the public interest.

When considering redefinition strategy for broadcasting, the two perspectives of public interest and regulatory balance must be taken into account. The more a mass medium has a duty to maintain public interest and universality in general viewing, the more regulation it should be under. Just as terrestrial broadcasters have been subject to stricter governmental control, so too should real-time programmed video services and VOD(Video on Demand) services also be regulated. This is because of the high degree of similarity between their content and that of terrestrial broadcasters. Furthermore, it it is clear that pay channels and on-line digital platforms together with growing and successful video services gradually erode revenue and advertising shares for terrestrial broadcasters that are no longer dominant market players.

Although Korean broadcasting regulation is asymmetrical, it has not been satisfactorily based on well-known concepts of broadcasting and public interest[11][12]. In order to make broadcast regulation more rational and to revitalize and balance the competing subgroups of the industry, the following suggestions have been made. 
(1) The definition of public interest and fairness in the law needs to be modified to include those duties most video services can maintain without harmful effects on society, a viewer's life, or effective competition. To this end, promoting locality, diversity, autonomy, and fair effective competition should become core elements of the public interest[9].

(2) Terrestrial broadcasters and cable TV platforms are currently suffering from the burdens of maintaining local programming that is an important element of public interest while other types of services do not have to provide it. It would therefore helpful to compensate terrestrial broadcasters for the costs incurred by local programming, and/or similar requirements should be imposed on the other types of video services.

(3) Compared to more developed countries, Korean terrestrial TV networks do not actually provide diverse and advanced UHD services such as MMS for multichannel programming, interactivity, and value-added convenience services. As this fact plays a significant role in decreasing viewer loyalty and increasing subscription rate of paid and on-demand services, the terrestrial networks need to create a variety of cutting-edge services as soon as possible.

(4) pay and on-demand services are becoming critically influential, and they must be regulated at a comparable level to terrestrial TV systems and must be reviewed on a case by case basis. Therefore, governmental authorities should keep tracks of up-to-date competing situations vigilantly and modify the current regulations concerning advertising sales and programming to create a fair competitive environment for all video service competitors.

\section{Conclusion}

The present situation in management and operations throughout the Korean broadcast system is not satisfactory because governmental and regulatory considerations among audio-visual services are unfair and fundamentally uncompetitive and do not promote the public interest at large. The most important thing for terrestrial broadcasters now is to recapture the loyalty of audience and advertisers who are increasingly evading traditional TV.

Thus, the term 'broadcasting' must be redefined to include all the audio-visual services and all these services must have an equal or a parallel degree of responsibility to show public interest programming in order to achieve a fair competitive plane in the broadcast field. It must also be stressed that increasing services for locality and diversity is one of broadcasters' main duties, and facilitating such an environment promotes autonomy and fair competition and so in turn, achieving this should be one of the main duties of the national government. 


\section{References}

[1] J. W. Lee, Asking Direction of Domestic Media Policy in the Age of Explosion of Media Services, Special Seminar of Korean Association for Broadcasting \& Telecommunication Studies, (2019), February 21; Seoul, Korea.

[2] J. H. Lee, The Legal Possibilities and Limitations of Local Broadcasting, Asian-pacific Journal of Convergent Research Interchange, (2019), Vol.5, No.1, pp.1-9, DOI: 10.21742/apjcri.2019.03.01

[3] Reports of Fact-Finding Survey on Broadcasting Industries, Ministry of Science, ICT and Future Planning and Korea Communications Commission, $(2014,2015,2016,2017,2018)$

[4] J. H. Lee, Inequality in Korean Local Broadcasting Policy, 2018 Winter Interdisciplinary Conference of Asia-pacific Society of Convergent Research Interchange, (2018), November 10; Daejeon, Korea.

[5] I. S. Jung, Structure of Broadcasting Industry, Communication Books, (2013)

[6] W. S. Hong, Horizontal Media Environment and Symmetric Media Regulation: Focusing on Terrestrial Broadcasting, Broadcasting Culture, (2017), Vol.410, No.3, pp.72-89.

[7] J. W. Lee, Asking Direction of Domestic Media Policy in the Age of Explosion of Media Services, Special Seminar of Korean Association for Broadcasting \& Telecommunication Studies, (2019), February 21; Seoul, Korea.

[8] J. H. Jeong, Redefinition of Broadcasting According to Change of Broadcasting Ecosystem, The 1st Media Policy Seminar of Korean Association for Broadcasting \& Telecommunication Studies, (2016), December 26; Seoul, Korea.

[9] D. N. Jeong and I. S. Jeong, Methods to Revise Regulation System through Redefinition of Broadcasting, Korea Broadcast Advertising Corporation, (2016)

[10] J. H. Jeong, Redefinition of Broadcasting According to Change of Broadcasting Ecosystem, The 1st Media Policy Seminar of Korean Association for Broadcasting \& Telecommunication Studies, (2016), December 26; Seoul, Korea.

[11] P. M. Napoli, Foundations of Communication Policy: Principles and Process in the Regulation of Electronic Media, Cresskill, Hampton Press, (2001)

[12] S. O. Yun, How to Define Public Interests of Broadcasting: Research on the Theory and Practice for Establishing Policy Objectives, Journal of Media Law, Ethics and Policy Research, (2013), Vol.12, No.1, pp.143-183, UCI: G704-001997.2013.12.1.002 